\title{
Human hypoxanthine-guanine phosphoribosyltransferase: a single nucleotide substitution in cDNA clones isolated from a patient with Lesch-Nyhan syndrome (HPRT Midland )
}

(Recombinant DNA; cDNA cloning; secondary structure prediction; hyperuricemia)

\author{
Beverly L. Davidson, Thomas D. Palella and William N. Kelley \\ Departments of Internal Medicine and Biological Chemistry and the Rackham Arthritis Research Unit, University of Michigan \\ Medical School, Ann Arbor, MI 48109 (U.S.A.)
}

Received 12 March 1988

Accepted 30 March 1988

Received by publisher 21 April 1988

\section{SUMMARY}

We have determined the molecular basis for hypoxanthine-guanine phosphoribosyltransferase (HPRT) deficiency in a patient, J.H., with Lesch-Nyhan syndrome. Radioimmunoassay of lysates of erythrocytes or cultured B-lymphoblasts showed that this patient had no detectable HPRT enzyme activity or HPRT protein. $H P R T$-specific mRNA levels were normal by Northern analysis.

We created a cDNA library from mRNA isolated from cultured lymphoblasts derived from this patient. Nucleotide sequencing of full-length HPRT cDNA clones revealed a single nucleotide (nt) substitution: a T-to-A transversion at $\mathrm{nt} 389$. We have designated this variant HPRT $_{\text {Midland }}$. The predicted amino acid (aa) substitution in HPRT $_{\text {Midland }}$ is a valine to aspartic acid at aa 130. This substitution is within 2 aa of the amino

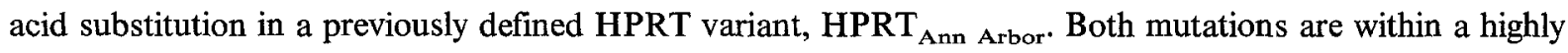
conserved sequence in the putative 5-phosphoribosyl-1-pyrophosphate-binding domain. The amino acid substi-

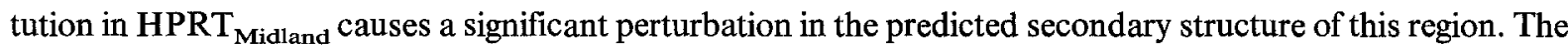
HPRT $_{\text {Midland }}$ mutation affects a different domain of HPRT than the HPRT $_{\text {Flint }}$ mutation located at $167 \mathrm{nt}$ away.

\section{INTRODUCTION}

Hypoxanthine-guanine phosphoribosyltransferase (HPRT) is a cytoplasmic enzyme involved in the salvage of purine bases. HPRT catalyzes the for-

Correspondence to: Dr. T.D. Palella, Department of Internal Medicine, University of Michigan Medical School, 1150 West Medical Center Drive, 5520 Medical Science Research Building I, Ann Arbor, MI 48109 (U.S.A.) Tel. (313)747-3413. mation of IMP and GMP from hypoxanthine and guanine, respectively. Partial deficiency of this enzyme results in overproduction of uric acid leading to severe, precocious gout and nephrolithiasis (Kelley et al., 1967). Virtually complete deficiency of

Abbreviations: aa, amino acid(s); bp, base pair(s); CRM, immunologically cross-reactive material: HPRT, hypoxanthineguanine phosphoribosyltransferase; HPRT, gene coding for HPRT; J.H., patient's initials; mU, milliunits; nt, nucleotide(s); PRPP, 5-phosphoribosyl-1-pyrophosphate. 
HPRT causes Lesch-Nyhan syndrome consisting of hyperuricemia, hyperuricaciduria and devastating neurological dysfunction, the hallmarks of which are mental retardation, spasticity, choreoathetosis and compulsive self-mutilation (Lesch and Nyhan, 1964; Seegmiller et al., 1967). The importance of the study of HPRT goes beyond these human diseases. Because of selection systems for both the HPRT ${ }^{+}$ and HPRT $^{-}$phenotypes, this protein and its gene have become important tools in genetic research (Szybalska and Szybalski, 1962; Rubin et al., 1971).

Subjects with HPRT deficiency reveal a striking degree of phenotypic and genotypic variety (Yang et al., 1984; Wilson et al., 1986a; Gibbs and Caskey, 1987). However, studies of the HPRT gene and mRNA from deficient subjects using Southern- and Northern-blot techniques are normal in most cases (Yang et al., 1984; Wilson et al., 1986a). Thus, more detailed analysis of IIPRT gene sequences is necessary to understand the molecular bases for enzymatic abnormalities.

Six mutant forms of HPRT from deficient subjects have been characterized previously at the molecular level. The amino acid substitutions in four mutant forms of HPRT were determined by amino acid sequencing of aberrant peptides derived from highly purified erythrocyte HPRT from deficient subjects (Wilson and Kelley, 1983a; Wilson et al., 1983b, 1984). This technique is limited to those HPRTdeficient subjects who express sufficient levels of HPRT protein for purification and amino acid sequence determination. Furthermore, this technique is time consuming and does not necessarily reveal the underlying mutation. More recently, we have exploited the observation that approximately $80 \%$ of HPRT deficient subjects have sufficient amounts of $H P R T$-specific mRNA for cDNA cloning in order to define the mutations in two other HPRT variants (Davidson et al., 1988; Fujimori et al., 1988).

Previously identified mutations in HPRT are widely scattered throughout the primary structure. HPRT $_{\text {Midland }}$, the mutant described in this study, is due to a single aa substitution located only two aa residues from a previously defined HPRT variant, HPRT $_{\text {Ann Arbor }}$ (Fujimori et al., 1988). Both mutations fall in the putative PRPP binding domain of IIPRT (Argos et al., 1983). Additionally, the region in which these mutations are found is conserved among different species.

\section{EXPERIMENTAL AND DISCUSSION}

\section{(a) Cell lines}

A patient (J.H.) with Lesch-Nyhan syndrome had undetectable levels of HPRT activity in both erythrocytes and cultured B-lymphoblasts $(<0.1$ $\mathrm{mU} / \mathrm{mg}$ or $<0.7 \%$ of control values) (Wilson et al., 1986a). In addition, levels of HPRT protein were undetectable as measured by radioimmunoassay using polyclonal anti-human HPRT antiserum ( $<1.5 \mathrm{ng} \mathrm{CRM} / \mathrm{mg}$ or $<0.5 \%$ of control values) (Wilson et al., 1986a). We have designated HPRT from this patient as $\mathrm{HPRT}_{\text {Midland. }}$.

$\mathrm{HPRT}_{\text {Ann Arbor }}$ was originally described as an HPRT variant on the basis of enzymatic properties (Wilson et al., 1982a). The mutation responsible for HPRT $_{\text {Ann Arbor }}$ has been defined (Fujimori et al, 1988). In contrast to J.II., this patient had partial HPRT deficiency with $10 \%$ of control levels of enzyme activity, and $11 \%$ of control values of CRM.

J.H. lymphoblasts were maintained in RPMI medium with $5 \%$ fetal calf serum as described previously (Wilson et al., 1982a).

\section{(b) cDNA cloning and isolation of recombinants}

Approximately $1.0 \mathrm{~g}$ (wet weight) of $\mathrm{HPRT}_{\text {Midland }}$ B-lymphoblasts was used for extraction of total RNA using guanidium isothiocyanate (Chirgwin et al., 1979) followed by oligo(dT) chromatography to select for poly(A) ${ }^{+}$RNA (Aviv and Leder, 1972). Oligo(dT) $)_{12-17}$ primed cDNAs were synthesized, using 5 to $20 \mu \mathrm{g}$ of poly(A) ${ }^{+}$RNA according to established procedures (Okayama and Berg, 1982; Gübler and Hoffman, 1983), and cloned in $\lambda \mathrm{gt} 11$ (Young and Davis, 1983).

The resultant cDNA library was screened with an $M s p \mathrm{I}-T a q \mathrm{I}$ fragment of normal human HPRT cDNA which represents 5 '-noncoding and coding sequences (Brennand et al., 1983). This 160-bp fragment was labeled with $\left[\alpha-{ }^{32} \mathrm{P}\right] \mathrm{dCTP}$ using hexadeoxynucleotide primers (Feinberg and Vogelstein, 1984).

Two HPRT -specific cDNA clones, pHPJH 1 and pHJH7, were isolated. Recombinant phages were purified from $20 \mathrm{ml}$ of phage lysate using standard techniques (Maniatis et al., 1982). The inserts were excised, separated from vector sequences and cloned 


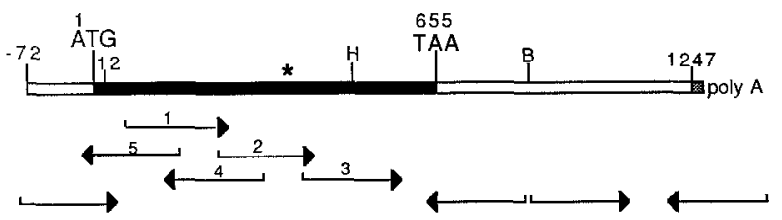

Fig. 1. Sequencing strategy for HPRT Midland $_{\text {CDNA clones }}$ pHPJH1 and pHPJH7. Both pHPJH7, which extends to nt -72 and PHPJH1, which extends to nt 12 were subcloned into the EcoRI site of M13mp18 or M13mp19 and sequenced with $H P R T$-specific oligodeoxynucleotide primers (arrows 1 through 5) and the M13 universal primer (unlabeled arrows). The nucleotide sequences of the HPRT-specific oligodeoxynucleotide primers are listed in Table I. The ATG start codon, TAA stop codon and poly(A) tail are indicated. The HindIII (H)-BalI (B) fragment $(255 \mathrm{bp})$ was subcloned into HindIII + SmaI-cut M13mp18 and M13mp19 for determination of 3 -noncoding sequences. These subclones were sequenced using the universal primer. The position of the mutation in pHPJH1 and $\mathrm{pHPJH} 7$ is indicated by the asterisk. Both clones were sequenced entirely in both directions. Open bar, $5^{\prime}$ and $3^{\prime}$ noncoding sequences; solid bar, coding sequences; stippled bar, poly(A) tail.

in M13mp18 and M13mp19 for isolation of singlestranded phages (Messing, 1983).

\section{(c) Sequencing and recombinant analysis}

Sequences of pHPJH1 and pHPJH7 were determined using the sequencing strategy described in Fig. 1. Single-stranded M13 recombinant phages were sequenced with $\left[\alpha-{ }^{35} \mathrm{~S}\right] \mathrm{dATP}$ (Biggin et al., 1983) using both the M13 universal primer and HPRT-specific primers. The sequences of the $H P R T$-specific primers are listed in Table I. Normal $H P R T$ cDNA contains $590 \mathrm{nt}$ of 3 '-noncoding sequence, $654 \mathrm{nt}$ of coding sequence, and from 110 to $170 \mathrm{nt}$ of $5^{\prime}$-noncoding sequences (Jolly et al., 1982;
Patel et al., 1986). Clone pHPJH7 consisted of 590 nt of $3^{\prime}$-noncoding sequence, $654 \mathrm{nt}$ of coding sequence, and $77 \mathrm{nt}$ of $5^{\prime}$-noncoding sequence. pHPJH1 lacks $17 \mathrm{nt}$ of coding sequence. Both clones were sequenced in their entirety in both directions (sense and antisense strands).

Recombinant clones pHPJH1 and pHPJH7 differed from normal human HPRT cDNA at a single nucleotide (Fig. 2): a T-to-A transversion at nt 389. This nucleotide substitution predicts a valine-toaspartic acid substitution at aa 130 (Fig. 3).

The mutation in HPRT Midland $_{\text {occurs in a region }}$ strongly conserved among human, rodent, and E. coli phosphoribosyltransferases (Table II). This was also the case in another HPRT variant with Lesch-Nyhan syndrome, HPRT Flint $_{\text {(Davidson }}$ et al., 1988). Such regions are probably important for maintenance of normal catalytic and kinetic properties as well as structural integrity. The effect of the valine-to-aspartic acid change in HPRT Midland $_{\text {and }}$ the resultant disruption of this conserved sequence may induce secondary and/or tertiary structural changes which render the protein more unstable, accounting for the lack of detectable activity and protein in this mutant.

The strongly conserved aa 129 through 137 have been implicated as part of the PRPP-binding domain (Argos et al., 1983). However, any catalytic consequence of the mutation in HPRT $_{\text {Midland }}$ cannot be determined because of insufficient residual protein

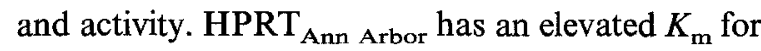
PRPP probably due to the isoleucine to methionine change at 132. As in HPRT Midland $_{\text {, the diminished }}$ amount of CRM in HPRT Ann Arbor $_{\text {may result from }}$ disruption of secondary or tertiary structure leading to enhanced proteolysis.

TABLE I

$H P R T$-specific oligodeoxynucleotides: sequences and sites of priming

\begin{tabular}{llcc}
\hline Oligodeoxynucleotide & Sequence $\left(5^{\prime}\right.$ to $\left.3^{\prime}\right)$ & $\begin{array}{l}\text { Priming site } \\
\text { (nt) }\end{array}$ & Strand $^{\text {a }}$ \\
\hline 1 & AGTGATGATGAACCAG & $31-47$ & - \\
2 & CACTGAATAGAAATAGT & $251-267$ & - \\
3 & GATATAATTGACACTGG & $403-419$ & - \\
4 & CCCCTGTTGACTGGTCA & $337-321$ & + \\
5 & AGTCCTGTCCATAATTA & $138-122$ & + \\
\hline
\end{tabular}

a The DNA strand to which the primer anneals is represented as either sense $(+)$ or antisense $(-)$. 


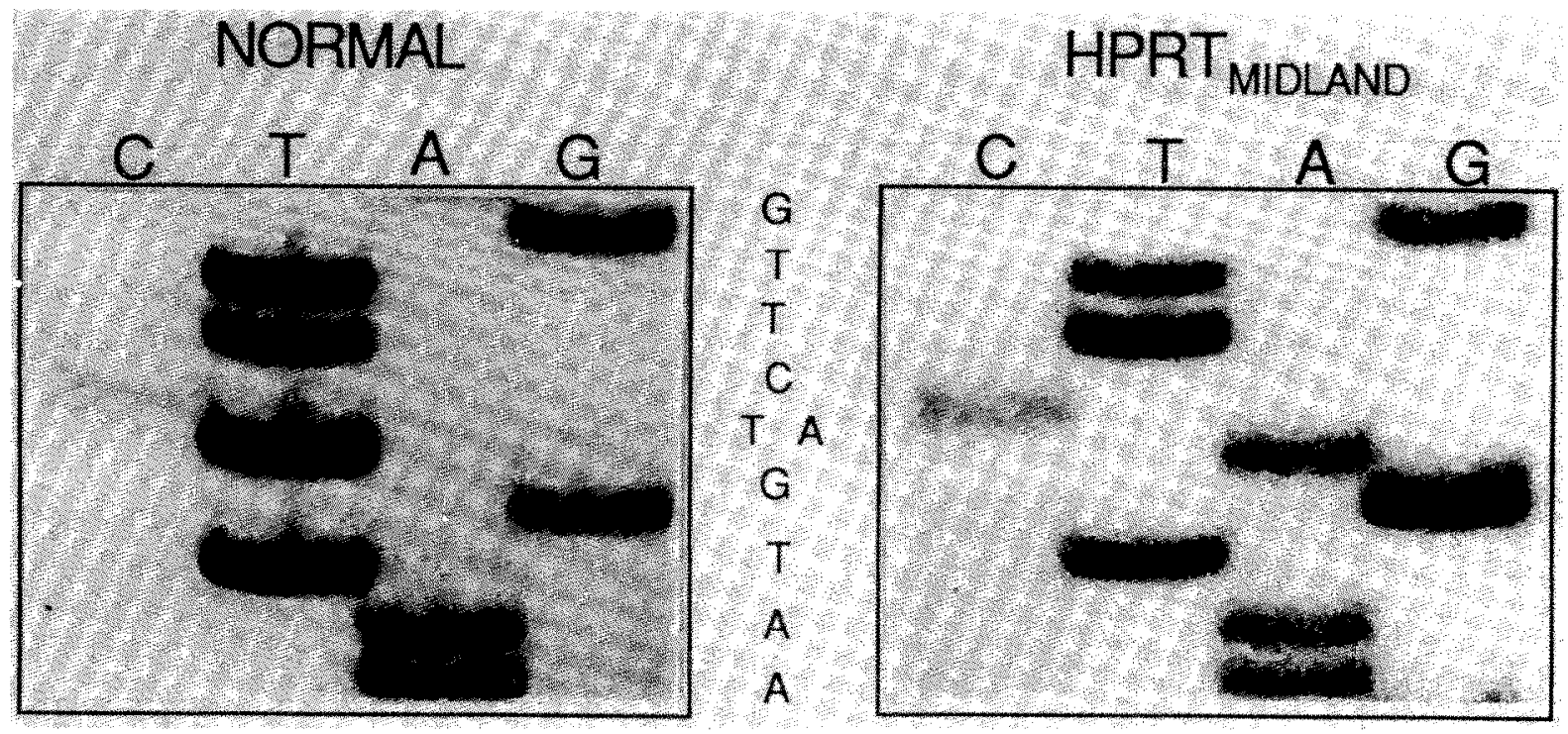

Fig. 2. The nucleotide substitution in HPRT Midland $_{\text {The sequencing gels for normal (left panel) and HPRT }}$ Midtand (right panel) DNAs are shown from nt 385-393. Single-stranded phages containing these sequences were sequenced using the dideoxynucleotide chain termination method according to Biggin (1983) using HPRT-specific primer 2 (Table I). One fourth of each sequencing reaction mix was electrophoresed on a $6 \%$ polyacrylamide gel containing $8 \mathrm{M}$ urea at constant power $(60 \mathrm{~W})$. The gels were then transferred to Whatman paper, dried under vacuum, autoradiographed for 2 to $8 \mathrm{~h}$, and developed. The sequence is shown between the panels with $\mathrm{T}$ (normal) transverted to an A (HPRT Midland $_{\text {. }}$.

\section{TABLE II}

The putative PRPP binding domain of various phosphoribosyltransferases ${ }^{\text {a }}$

\begin{tabular}{|c|c|c|c|c|c|c|c|c|c|c|}
\hline \multirow{2}{*}{$\begin{array}{l}\text { Phosphoribosyl- } \\
\text { transferase }^{b}\end{array}$} & \multicolumn{9}{|c|}{ Amino acids ${ }^{\circ}$} & \multirow[t]{2}{*}{ Reforence ${ }^{d}$} \\
\hline & 129 & 130 & 131 & 132 & 133 & 134 & 135 & 136 & 137 & \\
\hline Human HPRT (normal) & asn & val & leu & ile & val & glu & asp & ile & ile & A \\
\hline HPRT $_{\text {Midland }}$ & asn & asp & leu & ile & $\mathrm{val}$ & glu & asp & ile & ile & \\
\hline HPRT $_{\text {Ann Arbor }}$ & asn & val & leu & met & val & glu & asp & ile & ile & $\mathbf{B}$ \\
\hline Mouse HPRT & asn & yal & leu & ile & val & glu & asp & ile & ile & $\mathrm{C}$ \\
\hline Hamster HPRT & asn & val & leu & ile & val & glu & asp & ile & ile & D \\
\hline E. coli XGPRT & - & phe & ile & val & ile & asp & asp & leu & val & $\mathrm{E}$ \\
\hline Human APRT & $\arg$ & val & val & val & val & asp & asp & leu & leu & $\mathrm{F}$ \\
\hline Mouse APRT & $\arg$ & val & val & ile & val & asp & asp & leu & leu & G \\
\hline E. coli APRT & lys & val & leu & val & val & asp & asp & leu & leu & $\mathbf{H}$ \\
\hline E. coli OPRT & - & val & met & leu & val & asp & asp & - & val & I \\
\hline E. coli GlnPRT & asn & val & leu & lea & yal & asp & asp & ser & ile & $\mathbf{J}$ \\
\hline
\end{tabular}

a This sequence is within a 35 residue stretch of aa predicted to be involved in PRPP binding, as based on secondary structure homology to $E$. coli GlnPRT (Argos et al., 1983).

' XGPRT, xanthine-guanine phosphoribosyltransferase; APRT, adenine phosphoribosyltransferase; OPRT, orotate phosphoribosyltransferase; GinPRT, glutamine phosphoribosylpyrophosphate amidotransferase.

${ }^{c}$ Residue numbers are based on the amino acid sequence of human HPRT (Wilson et al., 1982b).

d A, Wilson et al. (1982b); B, Fujimori et al. (1988); C,D, Konecki et al. (1982); E, Pratt and Subramani (1983); F, Wilson et al. (1986b); G, Dush et al. (1985); H, Hershey and Taylor (1986); I, Poulsen et al. (1983); J, Tso et al. (1983).

- Normal sequence for the region from aa 129-137. 


$\begin{array}{llll}\text { HPRT }_{\text {Midland }} & \text { Asn } & \text { Asp } & \text { Leu } \\ & \text { AAT } & \text { GA]C } & \text { TTG } \\ & & & \\ & & & \\ \text { Normal } & \text { AAT } & \text { GTTC } & \text { TTG } \\ & \text { Asn } & \text { Val } & \text { Leu } \\ & & 130 & \end{array}$

Fig. 3. The nucleotide and corresponding amino acid substi-

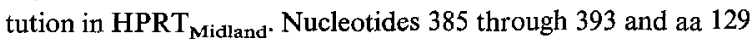
through 131 from both normal HPRT and HPRT Midland $_{\text {are }}$ shown. The nucleotide substitution is boxed.

\section{(d) Secondary structure predictions}

A computer-assisted analysis of predicted secondary structure perturbations caused by the amino acid substitutions in HPRT $_{\text {Midland }}$ was performed (Chou and Fasman, 1978). Hydrophilicity moments were also calculated and overlaid on the secondary structure plots (Hopp and Woods, 1981). The Sequence Analysis Software Package (Genetics Computer Group) for nucleic acid and protcin structure analysis was used for calculation and plotting of predicted structures (Wolf et al., 1988). This software is available through the University of Wisconsin Biotechnology Center, Madison, WI 53705. Predicted secondary structures for normal HPRT and HPRT Midland $_{\text {are shown in Fig. 4. The predicted }}$ secondary structure for normal HPRT from aa 115 to 145 consists of random $\operatorname{coil} / \beta$-sheet $/ \beta$-turn $/ \beta$ $\operatorname{turn} / \beta$-sheet. Valine, which has the strongest propensity towards forming $\beta$-sheet structure is replaced by

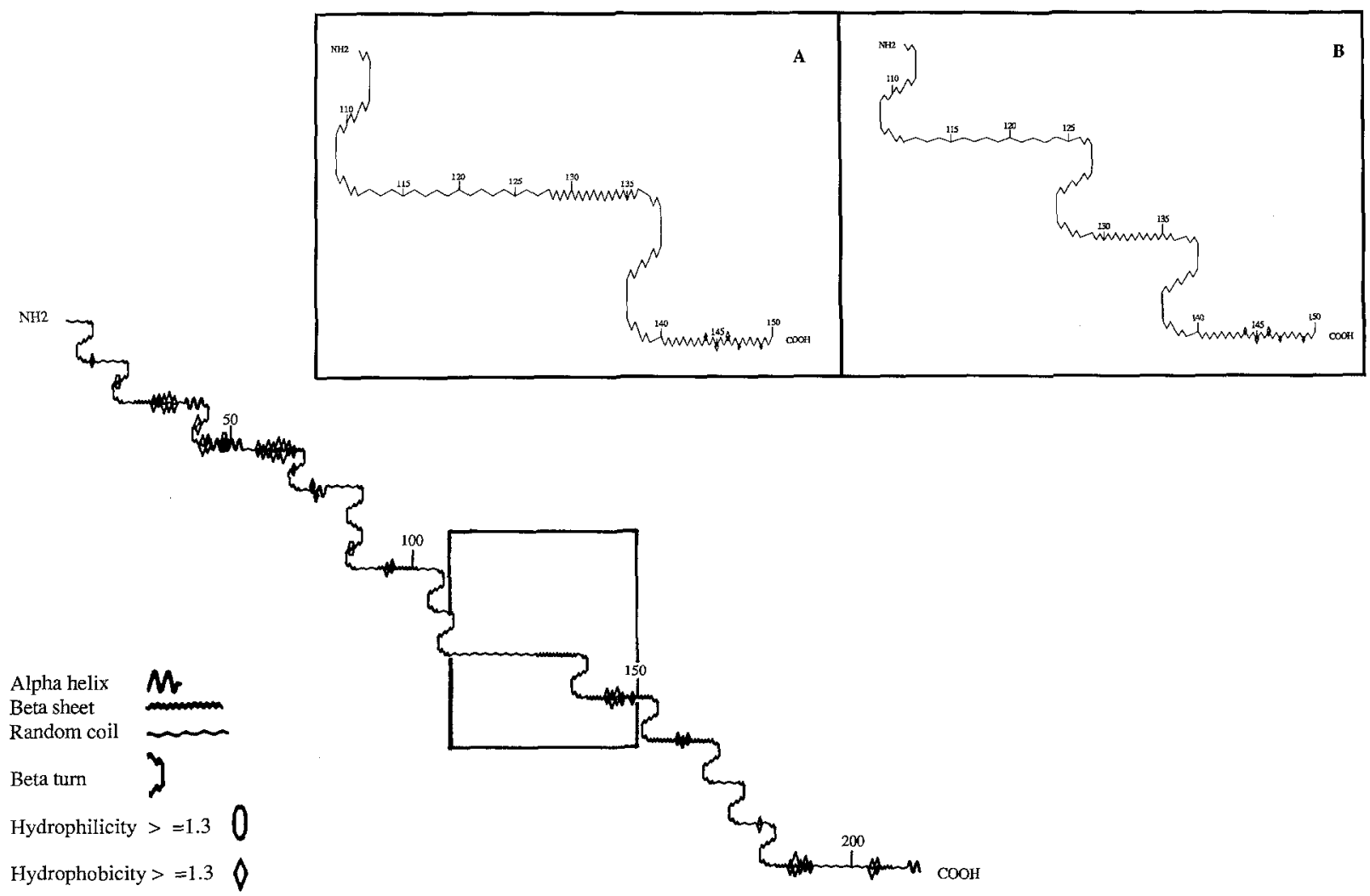

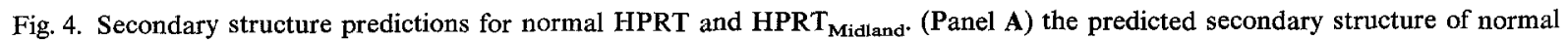
HPRT. The inset is an enlargement of the region contained within the box. (Panel B) The predicted secondary structure of HPRT $_{\text {Midland }}$ for the same region as the inset in panel $A$. The entire amino acid sequence for HPR' $\mathbf{H}_{\text {Midland }}$ and normal HPRT were analyzed using the PEPTIDESTRUCTURE and PLOTSTRUCTURE programs of the Genetic Computer Group nucleic acid and protein analysis package. The plot of the Chou-Fasman calculations includes regions of random coil, $\beta$-sheet, $\beta$-turn, and $\alpha$-helix, as illustrated in the

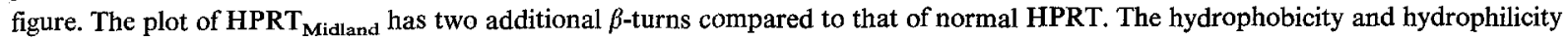
values (Hopp and Woods, 1981) are included in the secondary structure plots as diamonds and ovals, respectively. The size of the character is proportional to the magnitude of the attribute. 


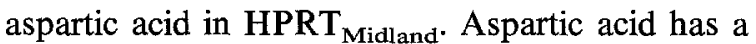
strong propensity to disrupt $\beta$-sheet structure and to form $\beta$-turn structure, especially in the context found in HPRT Midland (Chou and Fasman, 1978). The predicted result of this mutation on the secondary structure is the replacement of the first region of $\beta$-sheet structure by two additional $\beta$-turns beginning at or near aa 126 (Fig. 4).

\section{(e) Conclusions}

The genetic basis for enzyme deficiency in HPRT $_{\text {Midland }}$ has been determined by cDNA cloning. A single nucleotide alteration was determined by sequencing two cDNA clones derived from a subject with Lesch-Nyhan syndrome. The mutation in HPRT $_{\text {Midland }}$ is near the point mutation identified in HPRT $_{\text {Ann Arbor }}$, a variant with partial HPRT activity. The HPRT Midland mutation disrupts the putative PRPP binding domain which consists of a region of sequence of 9 aa strongly conserved among human, rodent and bacterial phosphoribosyltransferases. The structural alteration may impair protein stability leading to diminished amounts of CRM in cells derived from this subject. Altered secondary structure patterns are predicted for HPRT $_{\text {Midland }}$, consistent with this hypothesis. The HPRT Midland $_{\text {mutation is }}$ 167 nt away from a previously defined mutant, HPRT $_{\text {Flint }}$.

\section{ACKNOWLEDGEMENTS}

We would like to express our gratitude to Paul $\mathbf{R}$. Cauley and Mary E. Van Antwerp for expert technical assistance. We would also like to thank Ardith Listeman for expert secretarial assistance in the preparation of the manuscript. Normal HPRT cDNA was kindly provided by Dr. C. Thomas Caskey of Baylor University, Houston, TX. This work was supported by National Institutes of Health grant No. DK-19045. T.D.P. is the recipient of an Arthritis Investigator Award from the Arthritis Foundation.

\section{REFERENCES}

Argos, P., Hanei, M., Wilson, J.M. and Kelley, W.N.: A possible nucleotide binding domain in the tertiary fold of phosphoribosyltransferases. J. Biol. Chem. 258 (1983) 6450-6457.
Aviv, A. and Leder, P.: Purification of biologically active globin messenger RNA by chromatography on oligothymidylic acid cellulose. Proc. Natl. Acad. Sci. USA (1967) 1735-1739.

Biggin, M.D., Gibson, T.J. and Hong, G.F.: Buffer gradient gels and ${ }^{35} \mathrm{~S}$-label as an aid to rapid DNA sequence determination. Proc. Natl. Acad. Sci. USA 80 (1983) 3963-3965.

Bonthron, D.T., Markham, A.F., Ginsburg, D. and Orkin, S.H.: Identification of a point mutation in the adenosine deaminase gene responsible for immunodeficiency. J. Clin. Invest. 76 (1985) 894-897.

Chirgwin, J.M., Przybyla, A.E., MacDonald, R.J. and Rutter, W.J.: Isolation of biologically active ribonucleic acid from sources enriched in ribonuclease. Biochemistry 18 (1979) 5294-5299.

Chou, P.Y. and Fasman, G.D.: Empirical predictions of protein conformation. Annu. Rev. Biochem. 47 (1978) 251-276.

Davidson, B.L., Pashmforoush, M., Kelley, W.N. and Palella, T.D.: Genetic basis of hypoxanthine-guanine phosphoribosyltransferase deficiency in a patient with the Lesch-Nyhan

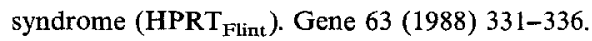

Dush, M.K., Sikela, J.M., Sohaib, A.K., Tischfield, J.A. and Stambrook, P.J.: Nucleotide sequence and organization of the mouse adenine phosphoribosyltransferase gene: presence of a coding region common to animal and bacterial phosphoribosyltransferases that has a variable intron/exon arrangement. Proc. Natl. Acad. Sci. USA 82 (1985) 2731-2735.

Feinberg, A.P. and Vogelstein, B.: A technique for radiolabeling DNA restriction endonuclease fragments to high specific activity. Anal. Biochem. 132 (1984) 6-13.

Fujinori, S., Hidaka, Y., Davidson, B.L., Palella, T.D. and Kelley, W.N.: Identification of a single nucleotide change in a mutant hypoxanthine-guanine phosphoribosyltransferase

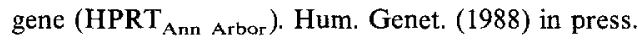

Gibbs, R.A. and Caskey, C.T.: Identification and localization of mutations at the Lesch-Nyhan locus by ribonuclease $A$ cleavage. Science 236 (1987) 303-305.

Gubler, H. and Hoffman, B.J.: A simple and very efficient method for generating cDNA libraries. Gene 25 (1983) 263-269.

Hershey, H.V. and Taylor, M.W.: Nucleotide sequence and deduced amino acid sequence of Escherichia coli adenine phosphoribosyltransferase and comparison with other analogous enzymes. Gene 43 (1986) 287-293.

Jolly, D.J, Okayama, H., Berg, P., Esty, A.C., Filpula, D., Bohlen, P., Johnson, G.G., Shively, J.E., Hunkapillar, T. and Friedmann, T.: Isolation and characterization of a full length expressible cDNA for human hypoxanthine-guanine phosphoribosyltransferase. Proc. Natl. Acad. Sci. USA 80 (1983) 477-481.

Konecki, D.S., Brennand, J, Fuscoe, J.C., Caskey, C.T. and Chinault, A.C.: Hypoxanthine-guanine phosphoribosyltransferase genes of mouse and Chinese hamster: construction and sequence analysis of cDNA recombinants. Nucl. Acids Res. 10 (1982) 6763-6775.

Kelley, W.N., Rosenbloom, F.M., Henderson, J.F. and Seegmiller, J.E.: A specific enzyme defect in gout associated with overproduction of uric acid. Proc. Natl. Acad. Sci. USA 57 (1967) 1735-1739. 
Lesch, M. and Nyhan, W.L.: A familial disorder of uric acid metabolism and central nervous system function. $\Lambda \mathrm{m}$. J. Med. 36 (1964) 561-570.

Maniatis, T., Fritsch, E.F. and Sambrook, J.: Molecular Cloning. A Laboratory Manual. Cold Spring Harbor Laboratory, Cold Spring Harbor, NY, 1982.

Messing, J.: New M13 vectors for cloning. Methods Enzymol. 101 (1983) 20-77.

Okayama, $\mathrm{H}$. and Berg, P.: High efficiency cloning of full-length cDNA. Mol. Cell. Biol. 2 (1982) 161-170.

Patel, P.I., Framson, P.E., Caskey, C.T. and Chinault, A.C.: Fine structure of the human HPRT gene. Mol. Cell. Biol. 6 (1986) 393-403.

Poulsen, P., Jensen, K.F., Valentine-Hansen, P., Carlsson, P. and Lundberg, L.G.: Nucleotide sequence of the Escherichia coli pyrE gene and of the DNA in front of the coding region. Eur. J. Biochem. 135 (1983) 223-229.

Pratt, D. and Subramani, S.: Nucleotide sequence of the Escherichia coli xanthine-guanine phosphoribosyltransferase gene. Nucl. Acids Res. 11 (1983) 8817-8823.

Rubin, C.S., Dancis, J., Lilly, C.Y., Nowinski, R.C. and Balis, M.E.: Purification of IMP: pyrophosphate phosphoribosyltransferase, catalytically incomplete enzymes in LeschNyhan disease. Proc. Natl. Acad. Sci. USA 68 (1971) 1461-1464.

Seegmiller, J.E., Rosenbloom, F.M. and Kelley, W.N.: Enzyme defect associated with a sex-linked human neurological disorder and excessive purine synthesis. Science 155 (1967) $1682-1684$.

Szybalska, E.H. and Szybalski, W.: Genetics of human cell lines, IV. DNA-mediated heritable transformation of a biochemical trait. Proc. Natl. Acad. Sci. USA 48 (1962) 2026-2034.

Wilson, J.M. and Kelley, W.N.: Molecular basis of hypoxanthineguanine phosphoribosyltransferase deficiency in a patient with the Lesch-Nyhan syndrome. J. Clin. Invest. 71 (1983) 1331-1335.

Wilson, J.M. and Kelley, W.N.: Human hypoxanthine-guanine phosphoribosyltransferase: structural alteration in a dysfunctional enzyme variant $\left(\right.$ HPRT $_{\text {Munich }}$ ) isolated from a patient with gout. J. Biol. Chcm. 259 (1984) 27-30.
Wilson, J.M., Baugher, B.W., Mattes, P.M., Daddona, P.E. and Kelley, W.N.: Human hypoxanthine-guanine phosphoribosyltransferase: demonstration of structural variants in lymphoblastoid cells derived from patients with a deficiency. J. Clin. Invest. 69 (1982a) 706-715.

Wilson, J.M., Tarr, G.E., Mahoney, W.C. and Kelley, W.N. Human hypoxanthine-guanine phosphoribosyltransferase: complete amino acid sequence of the erythrocyte enzyme. J. Biol. Chem. 257 (1982b) 10978-10985.

Wilson, J.M., Kobayashi, R., Fox, I.H. and Kelley, W.N.: Human hypoxanthine-guanine phosphoribosyltransferase: molecular abnormality in a mutant form of the enzyme (HPRT Toronto $_{\text {). }}$. J. Biol. Chem. 258 (1983a) 6458-6460.

Wilson, J.M., Tarr, G.E. and Kelley, W.N.: Human hypoxanthine-guanine phosphoribosyltransferase: an amino acid substitution in a mutant form of the enzyme isolated from a patient with gout. Proc. Natl. Acad. Sci. USA 80 (1983b) 870-873.

Wilson, J.M., Stout, J.T., Palella, T.D., Davidson, B.L., Kelley, W.N. and Caskey, C.T.: A molecular survey of hypoxanthineguanine phosphoribosyltransferase deficiency in man. J. Clin. Invest. 77 (1986a) 188-195.

Wilson, J.M., O'Toole, T.E., Argos, P.A., Shewach, D.S., Daddona, P.E. and Kelley, W.N.: Human adenine phosphoribosyltransferase. Complete amino acid sequence of the erythrocyte enzyme. J. Biol. Chem. 261 (1986b) 13677-13583.

Wolf, H., Modrow, S., Motz, M., Jameson, B., Hermann, B. and Fotsch, B.: An integrated family of amino acid sequence analysis programs. Comp. Appl. Biosci. (1987) in press.

Yang, T.P., Patel, P.I., Chinault, A.C., Stout, J.T., Jackson, L.G., Hildebrand, B.M. and Caskey, C.T.: Molecular evidence for new mutation at the HPRT locus in Lesch-Nyhan patients. Nature 310 (1984) 412-414.

Young, R.A. and Davis, R.W.: Efficient isolation of genes by using antibody probes. Proc. Natl. Acad. Sci. USA 80 (1983) 1194-1198.

Communicated by J.A. Engler. 